\title{
Research in general paediatrics
}

\section{H M Sammons, J McIntyre, I Choonara}

\section{Do district general hospitals have a role?}

$\mathrm{T}$

he aim of this leading article is to explore the important topic of research in general paediatrics. The need for research in this field will be reviewed along with where and who should be carrying this out. The role of district general hospitals (DGHs) in research in general paediatrics is discussed.

\section{WHY DO WE NEED RESEARCH IN GENERAL PAEDIATRICS?}

Decision making within medicine has correctly shifted towards evidence based practice. It is important to ensure that in the most common conditions seen in general paediatrics children receive the best treatment. There are still many situations, for example, treatment of acute seizures and sedation for procedures, which have outstanding therapeutic and management questions that need answering through research. The need to encourage research has been acknowledged by the inclusion of a general paediatric section in the Royal College of Paediatrics and Child Health Annual Meeting in York over the past few years.

A review of randomised controlled trials (RCTs) published in Archives of Disease in Childhood from 1982 to 1996 found 249 RCTs, with only $28 \%$ being classified as being within the area of general paediatrics. ${ }^{1}$ This suggests that much of our research potential is concentrated on rare conditions and neglects the more common general paediatrics.

\section{WHERE SHOULD RESEARCH IN GENERAL PAEDIATRICS BE PERFORMED?}

Research is often thought of as nonclinical and clinical research. Non-clinical research, such as molecular and animal studies, is usually performed in academic laboratory based facilities and gives us the ideas and theories that are carried through into our clinical research. Clinical research, such as that into new drug therapies, is usually carried out initially in healthy adult volunteers and then tested in the paediatric patient population. ${ }^{2}$ Therefore wherever there is a paediatric population of patients there is the potential for research. General paediatricians in DGHs have participated in large multicentre trials, for example, the OSIRIS trial of surfactant in preterm babies with respiratory distress. ${ }^{4}$

Most research is carried out in teaching hospitals. Relatively little research is carried out in either DGHs or primary care. DGHs cover a large proportion of the paediatric population in the UK. They therefore have a larger exposure to common general paediatric conditions than specialist tertiary centres. This is already being utilised for our medical students and junior doctors in their training with placements in DGHs. The recruitment of children is a major issue in clinical trials ${ }^{6}$ and health professionals need to ensure that large groups of children-that is, those within DGHs and the community are not excluded from research. ${ }^{7}$ Patients in DGHs and the community are also more likely to be representative of a paediatric condition than patients in specialist tertiary centres, where there will be a disproportionate number of severe cases.

We carried out a review of original articles in Archives of Disease in Childhood for the year 2001 (excluding personal practice, current topics, review articles, and case reports). There were 145 papers, of which $52 \%$ were UK based. Sixty two per cent of the papers were considered to be of a general paediatric nature-that is, of use to a general paediatrician in their practice in a DGH. From the UK papers, over $90 \%$ of original research in this year originated from tertiary referral centres, with only seven papers (9.6\%) having lead authors based at DGHs ${ }^{8-14}$ (table 1). All but one of these papers from DGHs involved areas of general paediatrics.

Many DGHs can also provide excellent facilities for children which are ideal for clinical research. Clinical trials in children need to be carried out in child friendly locations. Research into models for service development, such as attendance at outpatient clinics, ${ }^{15}$ and economic evaluation ${ }^{16}$ can also take place within the DGH setting. Research can also be performed at home. We are currently involved in studies of drug metabolism using breath tests and drug toxicity involving ECGs and interviews which have been carried out in the child's home. This is more convenient for both child and family.

\section{WHO SHOULD CARRY OUT RESEARCH IN GENERAL PAEDIATRICS?}

A simple answer to this would be any health care professional who is involved in the care of children. Many specialist registrars spend time during their training in the DGH setting.

They should have protected time in their working week to dedicate to professional development and research. This should help facilitate and stimulate research. Both the RCPCH and the Department of Health recommend that all consultants should be able to critically appraise research evidence. This implies the need for research experience by specialist registrars and for their consultant supervisors to have the skills to supervise this activity. Promotion and participation within research raises the

Table 1 Original papers published in Archives of Disease in Childhood in 2001 with lead author based in a DGH

\begin{tabular}{|c|c|}
\hline Title & Institution \\
\hline $\begin{array}{l}\text { Pain in cognitively impaired, non-communicating } \\
\text { children }^{8}\end{array}$ & Royal United Hospital, Bath \\
\hline $\begin{array}{l}\text { Persistent wheezing in infants with an atopic } \\
\text { tendency responds to inhaled fluticasone? }\end{array}$ & $\begin{array}{l}\text { The Royal Alexander Hospital for } \\
\text { Sick Children, Brighton }\end{array}$ \\
\hline $\begin{array}{l}\text { A novel scheme for reporting of adverse drug } \\
\text { reactions }\end{array}$ & Derbyshire Children's Hospital \\
\hline $\begin{array}{l}\text { Changes in paediatric resuscitation knowledge } \\
\text { among doctors }\end{array}$ & Derriford Hospital, Plymouth \\
\hline $\begin{array}{l}\text { Is regional paediatric surveillance useful? } \\
\text { Experience in Wales }\end{array}$ & Llandough Hospital, Penarth \\
\hline $\begin{array}{l}\text { Invasive procedures carried out in conscious } \\
\text { children: contrast between North America } \\
\text { and European paediatric oncology centres }\end{array}$ & Llandough Hospital, Penarth \\
\hline Recent trends in hospital use by children in England ${ }^{14}$ & Pinderfields Hospital, Wakefield \\
\hline
\end{tabular}


profile of research and evidence based medicine as a whole within these trusts.

Research is nowadays a multidisciplinary activity. Many research projects are run on a team basis in both primary and secondary care, ${ }^{17}$ with investigators coming from a nursing or pharmacy background. ${ }^{6}{ }^{18} 19$ No matter what the project, it is important to make all the professional groups aware of its impact on their own practice and get their support before starting a project.

\section{HOW CAN RESEARCH BE DONE?}

Research in children differs from that in adults because of the necessity to make research appropriate for the different age groups and also to address the issue of potential individual benefit for each child.

\section{Trial design}

Trials in children need to be discussed with a paediatrician, and in drug trials ideally a paediatric clinical pharmacologist or an experienced paediatric pharmacist. ${ }^{2}{ }^{3}$ Study design needs to consider the intended target population and have clear inclusion and exclusion criteria. Ethical issues need to be addressed early. A clear study question and simplicity is important.

\section{Statistical analysis}

Statistical analysis of the data and the number of patients needed within the protocol (that is, power calculations) need to be considered at an early stage. A basic guide such as Medical statistics: a common sense approach ${ }^{20}$ is a useful starting point and discussion with a statistician should take place. Many hospitals now have access to a medical statistician. One needs to understand the statistical tests one uses.

For large studies, there is a need to establish a database to record all the data. This is best done early so that data can be inputted as the study is being carried out. Software programmes such as Excel and SPSS are useful for this task. Clear hypotheses and questions that the data need to answer are required before starting the study-not after collection of the data.

\section{Funding}

Many research and development departments or local charities have small amounts of funding that may be used for the purpose of research projects. Larger scale studies require specific grant funding from a central organisation or charitable fund. A useful website is www.rdinfo.org.uk, which is a digest of health related research funding and training opportunities. Small studies can be carried out without additional funding. ${ }^{21} 22$ The difficulties of obtaining funding for research in general paediatrics in DGHs or for professions allied to medicine needs to be recognised. ${ }^{19}$

\section{Recruitment}

This has been one of the reasons cited why more paediatric research is not taking place. Recruitment of children into clinical trials has been considered a difficult problem to overcome. ${ }^{6}$ During the design of a study, the acceptability and convenience to both the family and child must be paramount to combat this. Therefore measures such as minimising blood taking and consideration of home visits (as opposed to bringing the child to hospital) should be considered.

\section{IS THIS RESEARCH GOOD FOR CHILDREN AND THEIR FAMILIES?}

Any research that can help provide evidence behind clinical practice is very important for the care of children. A review of informed consent, parental awareness, and reasons for parents participating in RCTs showed that the most frequent reason for participation was contribution to clinical science $(51 \%) .{ }^{23}$ Most families who take part in research are willing to participate in similar studies in the future. ${ }^{23}$

\section{HOW CAN WE TAKE RESEARCH IN GENERAL PAEDIATRICS FORWARD?}

For many doctors the time available for research is small. This may be one of the factors for the declining number of trials seen originating from DGHs. A possible answer to this is to try and foster more links between DGHs and academic units to allow more general paediatricians with dedicated time for research. Funding of research sessions alongside a reduction of excessive clinical duties need to be addressed $^{24}$ to enable research to take place.

Traditionally some DGHs have a history of research and affiliation with universities. An example of this is the university departments in Derby $^{6} 10171822$ and Penarth. ${ }^{11} 12$ Many other units such as Bath ${ }^{8}$ and Brighton have good links with their local universities and tertiary centres and a proven track record of research. Increasing medical student numbers may result in an increase of academic activity in DGHs. Creating a research network within general paediatrics and DGHs may be one way to promote research in this setting and field.

\section{IN CONCLUSION}

It is important that research in paediatrics addresses the common conditions as well as the rare. There is a large population of children with general paediatric conditions who are seen predominantly in the DGH setting. DGHs currently contribute only a small proportion to overall research in children. Both participation in multicentre trials and original research within this setting should be encouraged.

Arch Dis Child 2004;89:408-410.

doi: 10.1136/adc.2003.028290

\section{Authors' affiliations}

H M Sammons, J McIntyre, I Choonara, Academic Division of Child Health, University of Nottingham, Derbyshire Children's Hospital, Derby, UK

Correspondence to: Prof. I Choonara, Professor in Child Heath, Academic Division of Child Health, University of Nottingham, Derbyshire Children's Hospital, Clinical Sciences Building, Uttoxeter Road, Derby DE22 3DT, UK; imti. choonara@nottingham.ac.uk

Accepted 24 August 2003

\section{REFERENCES}

1 Campbell H, Surry SA, Royle EM. A review of randomised controlled trials published in Archives of Disease in Childhood from 1982-96. Arch Dis Child 1998:79:192-7.

2 Conroy S, Mclntyre J, Choonara I, et al. Drug trials in children: problems and the way forward. Br J Clin Pharmacol 2000;49:93-7.

3 Choonara I. Clinical trials of medicines in children. BMJ 2000;321:1093-4.

4 OSIRIS. Early versus delayed neonatal administration of a synthetic surfactant-the judgement of OSIRIS. The OSIRIS Collaborative Group (open study of infants at high risk of or with respiratory insufficiency-the role of surfactant. Lancet 1992;340:1363-9.

5 MacFaul R, Jones S, Werneke U. Clinical training experience in district general hospitals. Arch Dis Child 2000;83:39-44.

6 Peden V, Choonara I, Gennery B, et al. Recruiting children to a clinical trial. Paediatr Perinat Drug Ther 2000:4:75-8.

7 Bonati M. Primary care is natural place for clinical research and practice. BMJ 2000;321:1529

8 Stallard P, Williams L, Lenton S, et al. Pain in cognitively impaired, non communicating children. Arch Dis Child 2001:85:460-2.

9 Chavasse RJ, Bastian-Lee $\mathrm{Y}$, Richter $\mathrm{H}$, et al. Persistent wheezing in infants with an atopic tendency responds to inhaled fluticasone. Arch Dis Child 2001;85:143-8.

10 Clarkson A, Ingleby E, Choonara I, et al. A novel scheme for reporting of adverse drug reactions. Arch Dis Child 2001;84:412-14.

11 Carapiet D, Fraser J, Wade A, et al. Changes in paediatric resuscitation knowledge amongst doctors. Arch Dis Child 2001;84:412-14.

12 Sibert JR, Morgan RJH, O'Connell HI, et al. Is regional paediatric surveillance useful? Experience in Wales. Arch Dis Child 2001;84:486-7.

13 Hain RD, Campbell C. Invasive procedures carried out in conscious children: contrast between North America and European paediatric oncology centres. Arch Dis Child 2001;85:12-15.

14 MacFaul R, Werneke U. Recent trends in hospital use by children in England. Arch Dis Child 2001:85:203-7.

15 Gatrad AR. A completed audit to reduce hospital outpatient non-attendance rates. Arch Dis Child 2000;82:59-61

16 Bagust A, Haycox A, Sartain SA, et al. Economic evaluation of an acute paediatric hospital at home clinical trial. Arch Dis Child 2002;87:489-92 
17 Mclntyre J, Conroy S, Avery A, et al. Unlicensed and off label prescribing of drugs in general practice. Arch Dis Child 2000;83:498-501.

18 Conroy S, Mclntyre J, Choonara I. Unlicensed and off label drug use in neonates. Arch Dis Child Fetal Neonatal Ed 1999;80:F142-5

19 Rafferty AM Traynor M Thompson DR, et al. Research in nursing, midwifery, and the allied health professions. BMJ 2003;326:833-4.
20 Cambell M, Machin D. Medical statistics: a common sense approach. Willey Publication, 1990.

21 McCarthy C, Hewitt S, Choonara I. Pain in young children attending an A\&E department. J Accid Emerg Med 2000; 17:265-7.

22 Conroy S, Morton R, Dixon H, et al. A prospective study of intranasal midazolam for children with acute seizures. Paediatr Perinatal Drug Ther 2000;4:52-7.
23 Stuijvenberg MV, Suur MH, Vos SD, et al. Informed consent, parental awareness, and reasons for participating in a randomised controlled study. Arch Dis Child 1998;79:120-5.

24 Haggerty RJ, Sutherland SA. The academic general paediatrician: is the species endangered? Pediatrics 1999; 104:137-42.

\section{IMAGES IN PAEDIATRICS}

\section{From containers to classrooms: converting capitalism's swords into ploughshares}

$\mathrm{T}$

here are some ideas, which, when one hears them for the first time, come as a breath of fresh air, and capture one's imagination. Thare Machi-The Starfish Initiative-is one of these.

It converts shipping containers into classrooms for the developing world. Each container/classroom has eight IT desks, offering interactive lessons in the student's own language using DVD technology. No previous experience is required, nor is the ability to read or write. It is particularly designed to empower women and children, but it is open to all. In many parts of the world, women and girls as young as 8 are trapped, by their society, by their family, by their circumstances, by their poverty, and by their ignorance.

Girls are perceived to be costly so societies all over the world have developed ways of cutting down the expense. Education is regarded as one such luxury.

Shipping containers are a universal currency for the transport of goods and can be seen as a mechanism for the exploitation of the impoverished developing world by the West. Although their advent has revolutionised commerce they are not without their problems and issues regarding their dumping are being increasingly recognised.

Already the first containers are in use and supported by their local communities. The project aims to have several hundred of these containers in Africa and India within the next few years, with over 100 interactive lessons being available. Like seeding a desert of ignorance, these containers offer the first steps towards education. For many of the most deprived people on this planet without access to schools or teachers, this is their first real chance.

There are no quick fix solutions to the problems of injustice faced by the developing world, but this project and others like it provide a welcome step forward. Paediatricians with an interest in international child Health should strongly support this and other such noble endeavours.

Further information is available from www.starfish-initiative.org

A fully operational container classroom was exhibited during the entire 2004 Annual $\mathrm{RCPCH}$ Meeting in York
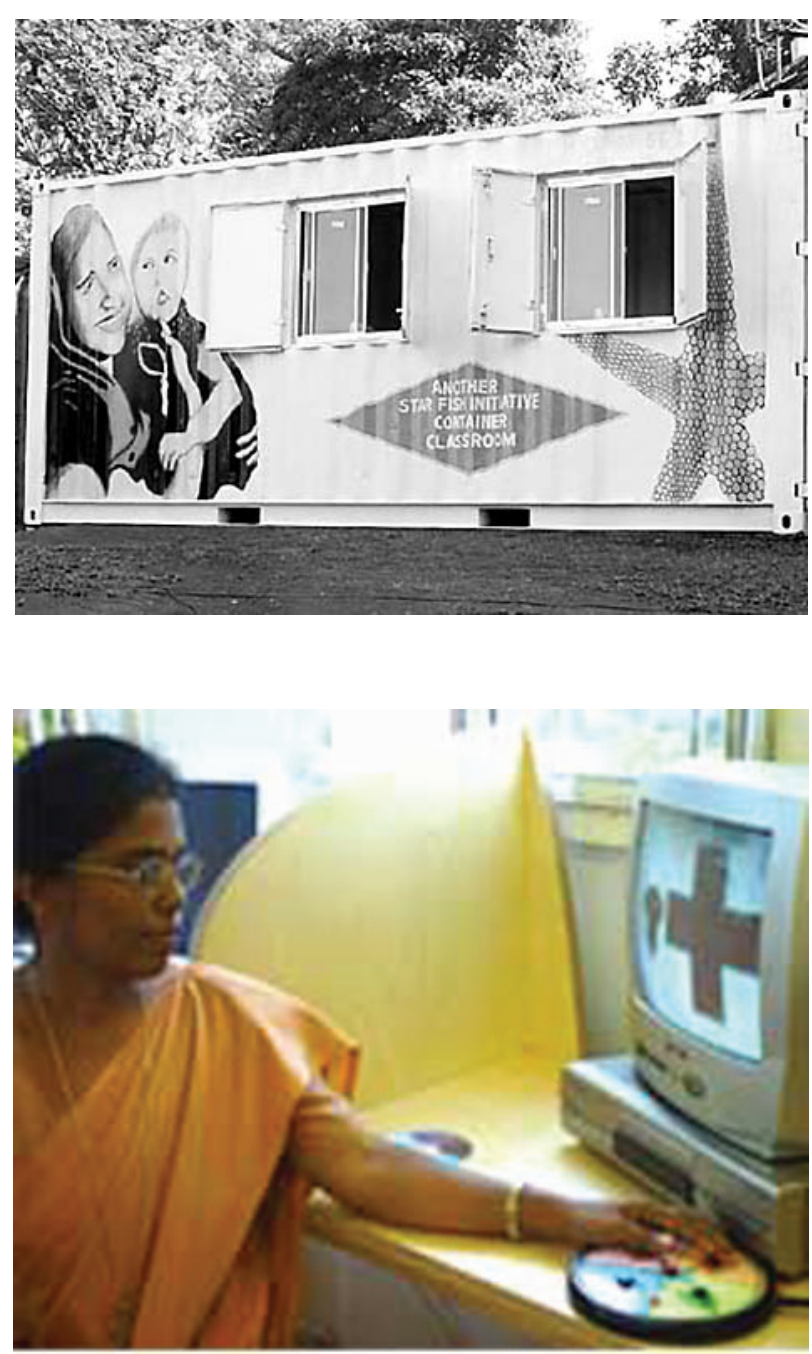

Acknowledgements: We would like to thank the Medical Illustration department of Northampton General Hospital

N Sellathurai, S Clarke, A N Williams Child Development Centre, Northampton General Hospital, Northampton NN1 5BD, UK; anw@doctors.org.uk 